\title{
Pharmacokinetic Evaluation by Modeling and Simulation Analysis of a Donepezil Patch Formulation in Healthy Male Volunteers
}

This article was published in the following Dove Press journal:

Drug Design, Development and Therapy

\author{
Seok Kyu Yoon' \\ Kyun-Seop Bae (D) \\ Dong Hyun Hong ${ }^{2}$ \\ Seong Su Kim ${ }^{2}$ \\ Young Kweon $\mathrm{Choi}^{2}$ \\ Hyeong-Seok Lim (ID) \\ 'Department of Clinical Pharmacology \\ and Therapeutics, College of Medicine, \\ University of Ulsan, Asan Medical Center, \\ Seoul, Republic of Korea; ${ }^{2}$ Department of \\ Pharmaceutical Research, iCure \\ Pharmaceutical Incorporated, Seoul, \\ Republic of Korea
}

Correspondence: Hyeong-Seok Lim Department of Clinical Pharmacology and Therapeutics, Asan Medical Center, University of Ulsan College of Medicine, Songpa-Gu, Seoul

Tel +82-2-30l 0-4623

Fax +82-2-3010-4622

Email mdlhs@amc.seoul.kr
Introduction: This study characterized the pharmacokinetics (PKs) of a donepezil patch formulation currently under development, using mixed effect modeling analysis, and explored optimal patch dosing regimens in comparison with the donepezil oral formulation.

Methods: PK data used in this analysis were from 60 healthy Korean male subjects participating in two Phase I studies, where subjects received single or multiple doses of donepezil of $43.75,87.5$, and $175 \mathrm{mg}$ via patches, and 12 of them received a single oral dose of $10 \mathrm{mg}$ of donepezil, followed by a single dose of donepezil via a patch. Donepezil PKs were analyzed by nonlinear mixed effect modeling using NONMEM software.

Results: A well-stirred model with two-compartment distribution and delayed absorption was chosen as the best model for the oral formulation. The PKs of donepezil after the patch applications were best described by a two-compartment linear model with zero-order absorption (D2) and absorption delay. The relative bioavailability (BA) of donepezil after the patch application compared with oral dosing was described to be affected by the duration of patch application.

Conclusion: PK simulations based on the chosen PK models suggested that, overall, donepezil exposure in plasma is similar whether with $10 \mathrm{mg}$ of oral donepezil every 24 h or a $175 \mathrm{mg}$ patch every $72 \mathrm{~h}$, and likewise with $5 \mathrm{mg}$ of oral donepezil every $24 \mathrm{~h}$ or an $87.5 \mathrm{mg}$ patch every $72 \mathrm{~h}$.

Keywords: clinical trial(s), clinical trial simulation(s), pharmacokinetics, pharmacometrics, analysis

\section{Introduction}

Dementia is characterized by persistent and general impairment of intellectual functions, such as memory, language ability, and judgment, that are related to the degeneration of brain function. Alzheimer's type dementia is the most common disease-causing cognitive dysfunction. ${ }^{1}$ In Alzheimer's dementia, $\beta$-amyloid is accumulated in specific regions of the brain, where it causes extensive abnormalities and, mainly, destruction of cholinergic neurons. In dementia, changes of protein expression were observed in the whole brain (including entorhinal cortex, cingulate gyrus, hippocampus, sensory cortex, motor cortex, and cervelli), not in specific parts of the brain. ${ }^{2}$ With this type, the number of cholinergic neurons is significantly decreased resulting in dementia, and so for these patients a treatment method that enhances the action of cholinergic nerves is used. ${ }^{3}$ 
Currently, the most widely used drugs for the treatment of dementia include donepezil, galantamine, and rivastigmine. They are reversible acetylcholinesterase inhibitors that inhibit cholinesterase enzyme to hydrolyze acetylcholine, increasing the amount of this neurotransmitter in the synaptic cleft. ${ }^{4-6}$

Donepezil is a well-known reversible non-competitive acetylcholinesterase inhibitor for the symptomatic treatment of Alzheimer's disease. ${ }^{7}$ Donepezil increases the amount of acetylcholine in the brains of patients, thereby activating the cholinergic neurons in the brain. It has been demonstrated through clinical trials the efficacy of donepezil in patients with mild, moderate, and severe Alzheimer's disease. ${ }^{8}$ Currently, the most commonly used formulations of acetylcholinesterase inhibitors are oral tablet form. However, in general, acetylcholinesterase inhibitors as oral agents frequently induce adverse effects such as gastrointestinal disorders and hepatic dysfunction $^{7}$ caused by elevated peripheral acetylcholine. ${ }^{9,10}$ To overcome these drawbacks, rivastigmine has already been developed as a patch formulation. ${ }^{11,12}$ Compared to oral formulation, patch formulation can reduce systemic maximum concentration of the drug by decreasing the absorption rate, and it can decrease the dosing frequency, increasing patient's compliance to treatment. A novel patch formulation of donepezil is under clinical development.

The purpose of the current study was to characterize the pharmacokinetics (PK) of a novel donepezil patch formulation using modeling and simulation analysis and to explore optimal dosing regimens for the patch in comparison with the oral formulation.

\section{Methods}

Modelling and Simulation analysis used to characterize the pharmacokinetics (PK) of donepezil patch formulation is based on datasets obtained from two clinical studies (NCT01860625 and NCT02178124), conducted in accordance with the International Conference on Harmonization (ICH), Good Clinical Practice (GCP) and the Declaration of Helsinki. Clinical Study Protocols and written subject information with informed consent form (ICF) have been submitted and approved by an Independent Ethics Committee (Asan Medical Center Institutional Review Board) prior to the start of the study.

\section{Data Included in the Analysis}

A total of 1049 plasma donepezil concentration values were used in this PK modeling analysis. PK analysis was conducted using the pooled data from the following two phase I studies in Korean male subjects: Study I. "A phase I clinical, Dose Escalation Study of the Safety, Tolerability and Pharmacokinetics of Donepezil Patch in Healthy Male Subjects (NCT01860625)", ${ }^{13}$ where subjects were given a placebo transdermal patch $(\mathrm{n}=3$ for each dose group) or a single patch containing a donepezil dose of $43.75,87.5$, or $175 \mathrm{mg}(\mathrm{n}=9$ in each of the three dose groups; 36 subjects in total). Tolerability and Pharmacokinetics of Donepezil Patch were already published in "Drug Design, Development and Therapy". ${ }^{13}$ In this study, problems with skin irritation were expected. However, the skin irritations to this study drug were mild. All skin irritations were resolved within 8 days. The adhesiveness of this patch was also excellent. Except for one subject, adhesiveness was over $50 \%$ for 72 hours. $^{13}$

Bloods for PK analysis were drawn at $0 \mathrm{~h}$ (pre-dose), 4 h, 8 h, 12 h, 24 h, 48 h, 70 h, 72 h, 74 h, 76 h, 80 h, 96 h, $120 \mathrm{~h}, 144 \mathrm{~h}, 168 \mathrm{~h}, 216 \mathrm{~h}, 264 \mathrm{~h}$, and $312 \mathrm{~h}$ after the drug product administration. Study II.

"A Phase I Clinical Study, Randomized, Single-blind, Placebo-controlled, Multiple Doses, Dose Escalation Study of the Safety, Tolerability and Pharmacokinetics of Donepezil Patch in Healthy Male Subjects (NCT02178124)" in 24 healthy subjects, where each subject was initially administered a single dose of donepezil oral formulation (except in the cohort dosing group 1), followed by multiple doses of donepezil transdermal patches. In this study, subjects in dose group 1 received either continuous application of a $87.5 \mathrm{mg}$ donepezil patch $(n=9)$ or a placebo patch $(n=3)$ over $15 \mathrm{~d}$ with patch renewal every $3 \mathrm{~d}$. Subjects in dose group 2 either received a single oral dose of $10 \mathrm{mg}$ of donepezil $(\mathrm{n}=9)$ or a placebo $(n=3)$ in period 1 , followed by a continuous application of a $175 \mathrm{mg}$ donepezil patch over $15 \mathrm{~d}$ (patch renewal every $3 \mathrm{~d}$ ) in period 2. Before starting the next period, a washout period of at least 20 days was accomplished to remove the carryover effect. In group 1, blood samples were collected

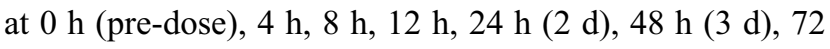
h (4 d), 144 h (7 d), 216 h (10 d), 288 h (13 d, final patch renewal), 292 h, 296 h, 300 h, 312 h (14 d), 336 h (15 d), $360 \mathrm{~h}$ (16 d, patch removal), $362 \mathrm{~h}, 364 \mathrm{~h}, 368 \mathrm{~h}, 372 \mathrm{~h}$, 384 h (17 d), 408 h (18 d), 432 h (19 d), 480 h (21 d), $528 \mathrm{~h}(23 \mathrm{~d})$, and $576 \mathrm{~h}(25 \mathrm{~d})$ after the first drug administration, and for subjects of group 2 in period 1, blood was drawn at $0 \mathrm{~h}$ (pre-dose), $0.5 \mathrm{~h}, 1 \mathrm{~h}, 1.5 \mathrm{~h}, 2 \mathrm{~h}, 3 \mathrm{~h}, 4 \mathrm{~h}$, 8 h, 12 h, 24 h (2 d), 48 h (3 d), 96 h (5 d), 144 h (7 d), 192 h $(9 \mathrm{~d})$, and $240 \mathrm{~h}(11 \mathrm{~d})$ after the oral dosing, and in 
period 2, at $0 \mathrm{~h}$ (pre-dose), $4 \mathrm{~h}, 8 \mathrm{~h}, 12 \mathrm{~h}, 24 \mathrm{~h}(2 \mathrm{~d}), 48$ h (3 d), 72 h (4 d), 144 h (7 d), 216 h (10 d), 288 h (13 d, final patch renewal), $292 \mathrm{~h}, 296 \mathrm{~h}, 300 \mathrm{~h}, 312 \mathrm{~h}$ (14 d), 336 h (15 d), 360 h (16 d, patch removal), 362 h, 364 h, 368 h, 372 h, 384 h (17 d), 408 h (18 d), 432 h (19 d), 480 h (21 d), $528 \mathrm{~h}(23 \mathrm{~d})$, and $576 \mathrm{~h}(25 \mathrm{~d})$ after the start of the first patch application.

Plasma donepezil concentrations were measured by validated liquid chromatography-tandem mass spectrometry (LC-MS/MS). HPLC (non-space SI-2 3133; Japan Tokyo do Shiseido) and the Unison UK-C18 column (3.0 $\mu \mathrm{m}, 50 \mathrm{~mm} * 2.0 \mathrm{~mm}$; Japanese Kyoto Im-tact) were used to analyze the sample extract. The MS system (API4000TM; AB Sciex, Framingham, MA, USA) operated through positive ion electrospray mode. Calibration curves covered the concentration from 0.1 to $80 \mathrm{ng} / \mathrm{mL}$. Inter-day accuracy ranged from $96.27 \%$ to $105.98 \%$, and inter-day precision $(\% \mathrm{CV})$ ranged from $0.7 \%$ to $4.3 \%{ }^{13}$

There was no statistically significant difference in the demographic characteristics of the subjects included in this analysis among dose groups with $26.4 \pm 4.4$ years in age [mean \pm standard deviation], $174.4 \pm 6.1 \mathrm{~cm}$ in height, and $70.4 \pm 7.8 \mathrm{~kg}$ in weight (Table 1).

\section{Pharmacokinetic Modeling Analysis}

PK analysis was conducted by nonlinear mixed effect modeling using NONMEM version 7.3 (ICON Development Solutions, Ellicott City, MD, USA), and data processing and plotting were performed using $\mathrm{R}$ version 3.1.2. NONMEM subroutines ADVAN13 and first-order conditional estimation (FOCE) with INTERACTION method were used. Various linear and nonlinear PK models were tested.
The parameters for a specific subject (i) were described by the following equation:

$$
\mathrm{Pi}=\mathrm{P}_{\mathrm{TV}} \times \exp (\eta)
$$

where $\mathrm{P}_{\mathrm{TV}}$ is the population typical value for the parameter and $\eta$ is a normally distributed random variable with a mean of zero and variance $\omega^{2}$.

Various structural and error models were assessed, guided by a graphical assessment of optimum fit properties and statistical significance criteria. A likelihood ratio test was used to discriminate between hierarchic models at $\mathrm{p}<0.05$, based on the fact that the difference of $-2 \log$ likelihood of the models approximately follows a chisquare distribution. Standard goodness-of-fit plots including the observed values of the dependent variable (DV), versus the individual predicted values (IPRE), and IPRE versus the individual weighted residuals were used for the diagnosis of optimum fit capabilities. A $90 \%$ prediction interval between the model and real, observed data was compared by visual predictive check plots. Nonparametric bootstrap with 1000 replicates was conducted, and the mean and 95\% confidence interval (2.5-97.5 percentile) were displayed together.

\section{Monte-Carlo Simulation for Donepezil PK Comparison}

Based on the final PK models for oral and patch donepezil formulations, Monte-Carlo simulations for plasma donepezil concentrations over time were conducted for the various dosing regimens. The simulated data for oral and patch formulations were compared with each other, and thereby were used to guide the optimal dosing regimens of the novel donepezil patch formulation. Area under the

Table I Baseline Demographic Characteristics of Subjects Used in the Current PK Analysis.

\begin{tabular}{|c|c|c|c|c|c|c|}
\hline & \multicolumn{5}{|c|}{ Donepezil Dose Groups } & \multirow[t]{2}{*}{ Total } \\
\hline & $\begin{array}{l}43.75 \mathrm{mg} \\
\text { Patch }(\mathrm{n}=9)\end{array}$ & $\begin{array}{l}87.5 \mathrm{mg} \\
\text { Patch }(\mathrm{n}=9)\end{array}$ & $\begin{array}{l}\text { I75 mg Patch } \\
(n=9)\end{array}$ & $\begin{array}{l}\text { Multiple } \\
\text { Doses of } 87.5 \\
\text { mg Patch } \\
(n=9)\end{array}$ & $\begin{array}{l}10 \mathrm{mg} \text { Single } \\
\text { oral Dose + } \\
\text { Multiple Doses } \\
\text { of } 175 \mathrm{mg} \text { Patch } \\
(n=12)\end{array}$ & \\
\hline Age, years & $27.9 \pm 5$ & $28.3 \pm 6.6$ & $24.9 \pm 3.3$ & $24.7 \pm 1.9$ & $26.1 \pm 3.7$ & $26.4 \pm 4.4$ \\
\hline Weight, kg & $71.1 \pm 9.6$ & $68.5 \pm 5.1$ & $71.2 \pm 8$ & $67.6 \pm 6.9$ & $72.9 \pm 8.8$ & $70.4 \pm 7.8$ \\
\hline Height, cm & $|76| \pm 6.7$. & $171.7 \pm 4.9$ & $175.2 \pm 6.8$ & $172.3 \pm 6.8$ & $176.3 \pm 4.9$ & $174.4 \pm 6.1$ \\
\hline
\end{tabular}

Note: Data are expressed as mean ( \pm standard deviation).

Abbreviations: PK, pharmacokinetics; kg, kilogram. 
curve (AUC) and steady state plasma concentrations based on the simulated data were also calculated and compared between the two formulations.

\section{Results}

\section{Pharmacokinetic Modeling}

Final PK modeling for the two formulations was conducted sequentially. In the first stage, PK for the oral formulation was fitted. In the second stage, the PK data from both oral and patch formulations were modeled after fixing oral absorption-related parameters such as the absorption rate constant $(\mathrm{Ka})$ and absorption delay (ALAG1) as the estimates from the previous fitting. This sequential approach better described the PK data for the oral formulation than simultaneous analysis of both formulations. For the final PK model of the oral formulation, a well-stirred model with two-compartment distribution and delayed absorption was chosen with saturated first pass metabolism and saturated systemic clearance described by Michaelis-Menten (MM) equation. ${ }^{14}$ A model with conventional first-order absorption kinetics severely underpredicted the concentration especially during the absorption phase, which was improved by implementing the well-stirred model. Introduction of additional linear clearance independent of the systemic clearance by well-stirred model also improved the fitness of the model significantly. The depot compartment for patch formulation was allocated compartment 2 separately from the compartment 1 for oral formulation. The PK of donepezil for patch application was best described by a twocompartment linear model with zero-order absorption (D2), and absorption delay (ALAG2). The relative bioavailability (BA) of donepezil after the patch application compared to oral dosing was described to be affected by the duration of patch application, and to be different between study I and II by the following equation:

$$
\mathrm{F} 2=\mathrm{IFF}_{\text {Study I or Study II }} * \text { PDUR/ADUR }
$$

where $\mathrm{F} 2$ is individual relative $\mathrm{BA}$ in the depot compartment (compartment 2) for the patch estimated by NONMEM, IFF2 is the individual baseline relative $\mathrm{BA}$ for the patch when applied for $72 \mathrm{~h}$, which was modeled by the separate parameters for each of the two clinical trial studies included in this analysis, PDUR is the planned duration of patch application (72 $\mathrm{h}$ in the current clinical trial), and ADUR is the actual duration of patch application in the trial. Introduction of interoccasion variability did not improve the model.
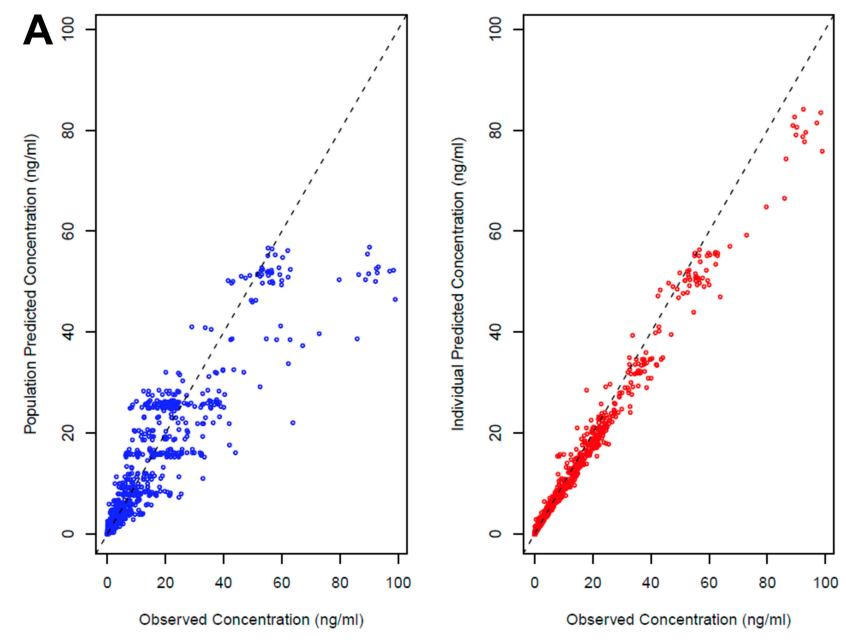

Donepezil oral formulation
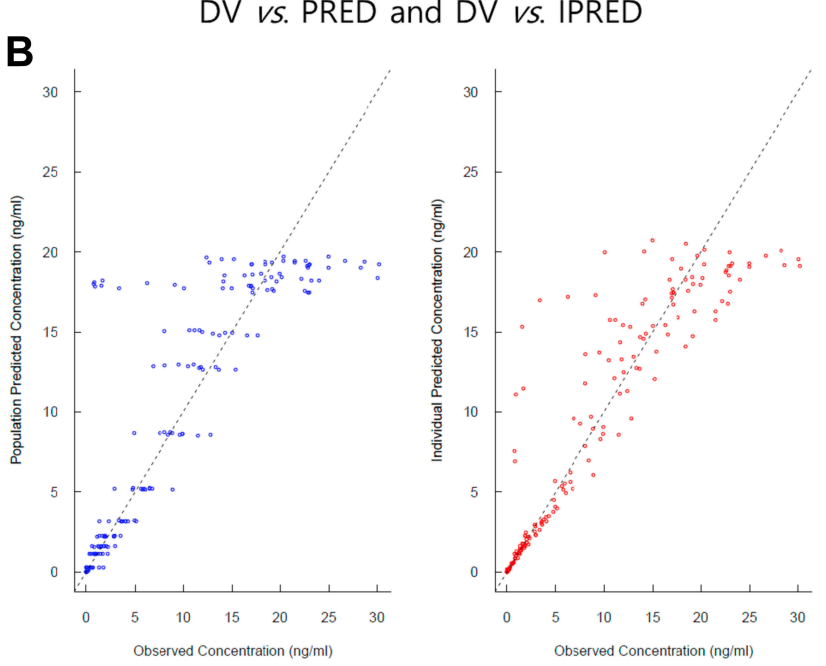

Donepezil patch formulation PRED VS. DV and DV vs. IPRED

Figure I Basic goodness-of-fit (DV vs PRED, and DV vs IPRED) for PK models after (A) donepezil oral formulation and (B) donepezil patch formulation.

Abbreviations: DV, dependent variable; PK, pharmacokinetics; PRED, population predictions; IPRED, individual predictions.

In the basic goodness-of-fit plots, no significant trend was observed for PK models of oral and patch formulations (Figure 1). The final PK model predicted the real, observed concentration data of both formulations reasonably well (Figure 2). In the PK model developed for the oral administration, the absorption rate constant $(\mathrm{Ka})$, apparent central volume of distribution $(\mathrm{Vd})$, peripheral $\mathrm{Vd}$, maximum velocity $\left(\mathrm{V}_{\max }\right)$, and concentration at half- $\mathrm{V}_{\max }\left(\mathrm{K}_{\mathrm{m}}\right)$ in the $\mathrm{MM}$ equation were estimated to be $4.46 \mathrm{~L}, 456.47 \mathrm{~L}, 516.91 \mathrm{~L}, 376.16 \mathrm{mg} / \mathrm{h}$, and 107.08 $\mathrm{ng} / \mathrm{mL}$, respectively. In the PK model developed for the patch administration, the duration of zero-order absorption (D2), absorption delay (ALAG2), central Vd, 


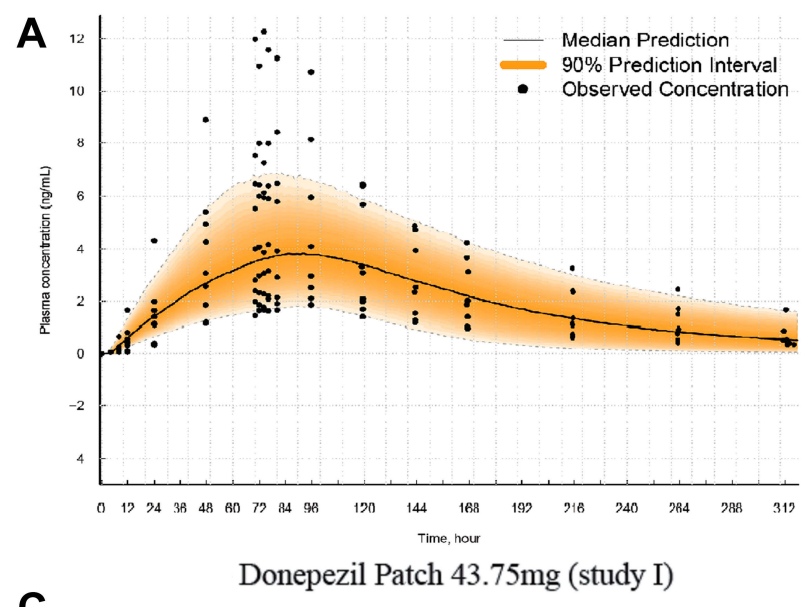

C

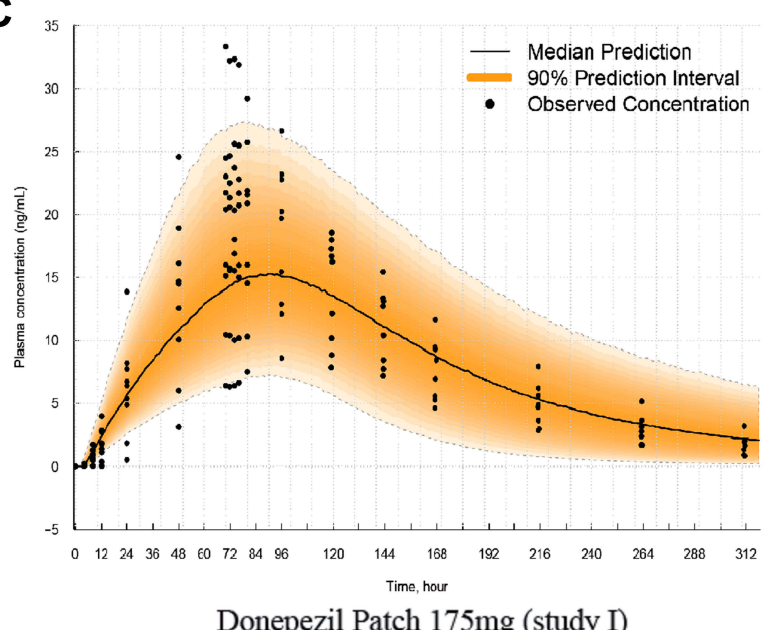

Donepezil Patch 175mg (study I)

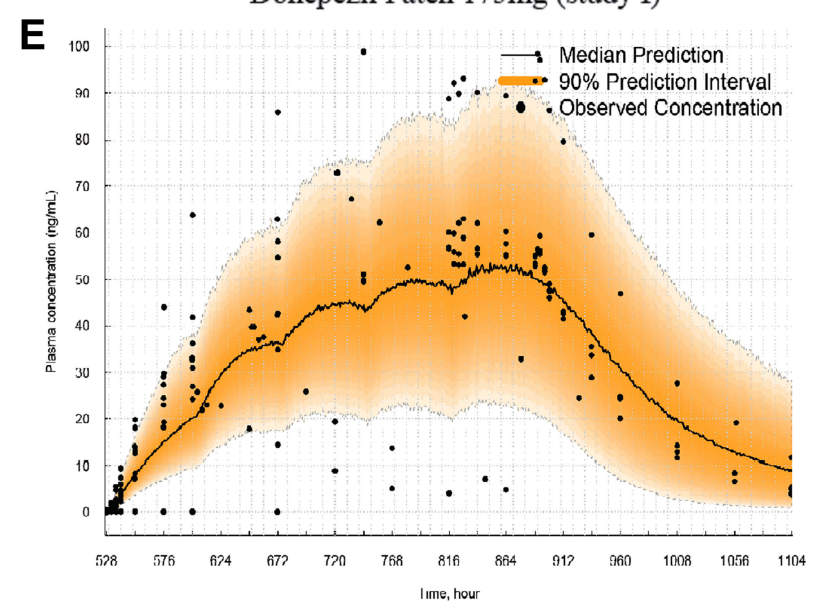

Donepezil Patch $175 \mathrm{mg}$ every $72 \mathrm{~h}$ (study II)

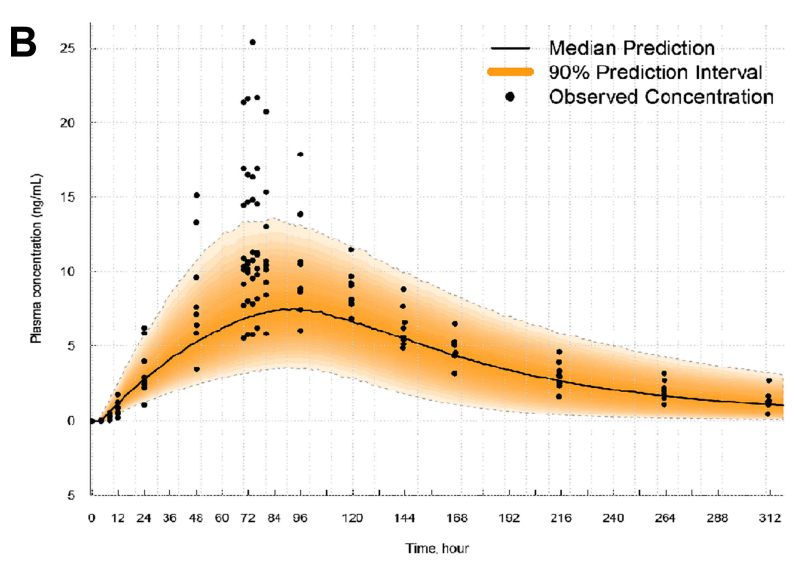

Donepezil Patch $87.5 \mathrm{mg}$ (study I)

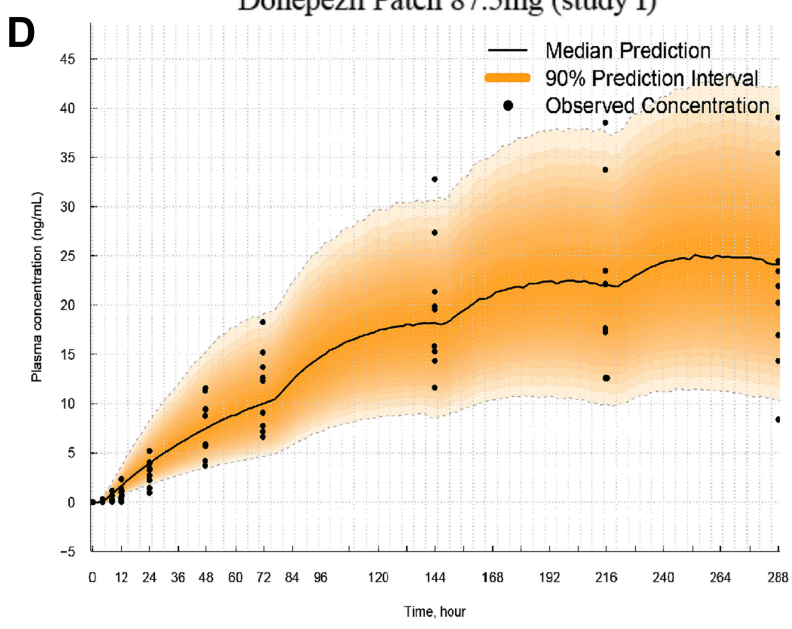

Donepezil Patch $87.5 \mathrm{mg}$ every $72 \mathrm{~h}$ (study II)

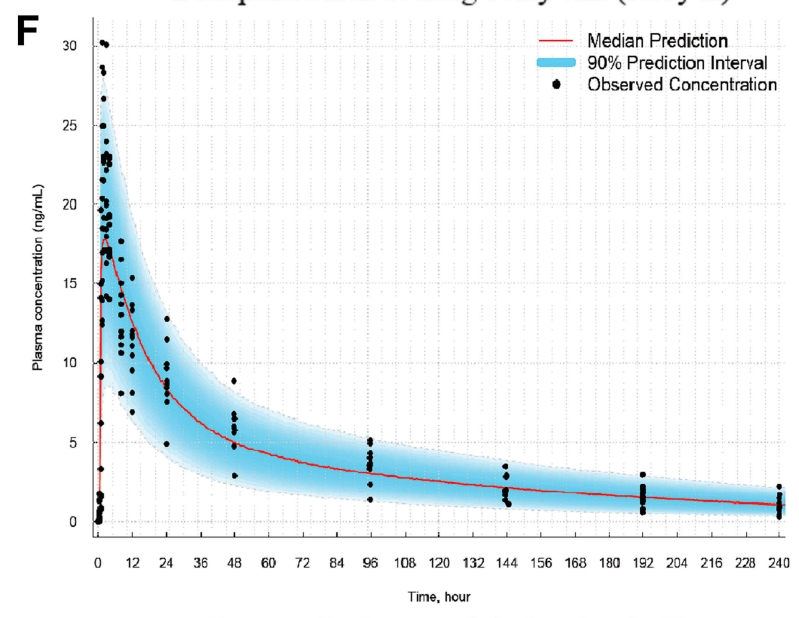

Donepezil $10 \mathrm{mg}$ oral dosing (study II)

Figure 2 Visual predictive check plots for PK models.

Abbreviation: PK, pharmacokinetics.

peripheral $\mathrm{Vd}, \mathrm{V}_{\max }$, and $\mathrm{K}_{\mathrm{m}}$ in the $\mathrm{MM}$ equation were estimated to be $97.4 \mathrm{~h}, 3.96 \mathrm{~h}, 697.6 \mathrm{~L}, 351.88 \mathrm{~L}$, $254.9 \mathrm{mg} / \mathrm{h}$, and $62.2 \mathrm{ng} / \mathrm{mL}$, respectively. Baseline relative BAs of the patch (IFF2) compared to with that of the oral formulation were estimated to be 0.13 for study I, and 0.18 for study II.

The parameter estimates from a single NONMEM run, and the bootstrap results, were similar for the 
patch and oral formulations. The PK parameter estimates for oral donepezil are summarized in Table 2(A), and for the donepezil patch in Table 2(B).

\section{Monte-Carlo Simulation}

The Monte-Carlo simulation of the plasma donepezil concentration predicted that a $10 \mathrm{mg}$ oral dose every $24 \mathrm{~h}$ and a $175 \mathrm{mg}$ donepezil patch every $72 \mathrm{~h}$ gave comparable overall plasma exposure to donepezil, as did a $5 \mathrm{mg}$ oral dose every $24 \mathrm{~h}$ and an $87.5 \mathrm{mg}$ donepezil patch every $72 \mathrm{~h}$, although with a slightly higher $72 \mathrm{~h}$ interval AUC at steady state, as demonstrated by the patch/oral dosing AUC ratios of 1.23 and 1.22 , respectively.

The differences in exposure between the dosing regimens might have been predicted to decrease further by increasing the dosing intervals of the patch to $84 \mathrm{~h}$; however, $84 \mathrm{~h}$ or 72 and $96 \mathrm{~h}$ (dosing interval is alternatingly $72 \mathrm{~h}$ and $96 \mathrm{~h}$ ) patch interval regimens for the $87.5 \mathrm{mg}$ and $175 \mathrm{mg}$ patches also

Table 2 Parameter Estimates, Bootstrap Mean and Bootstrap 95\% Confidence Interval for Donepezil Plasma Concentrations After Dosing with (A) Oral Formulation and (B) Patch Formulation

\begin{tabular}{|c|c|c|c|}
\hline \multicolumn{4}{|l|}{ (A) } \\
\hline & Estimates & Bootstrap Mean & Bootstrap $95 \% \mathrm{Cl}^{\dagger}$ \\
\hline $\mathrm{Ka}, \mathrm{h}$ & 4456 & 3.69 & I.53-7.26 \\
\hline $\mathrm{IIV}_{\mathrm{Ka}}(\mathrm{CV} \%)^{£}$ & I.2I (II.II\%) & 0.99 (9.95\%) & $0.05-1.9$ \\
\hline ALAGI, h & 0.497 & 0.51 & $0.48-0.5$ \\
\hline Vc, L & 456.473 & 442.97 & $369.99-497.2$ \\
\hline$I I V_{V_{c}}(C V \%)^{f}$ & 0.002 (6.07\%) & 0 (6.07\%) & $0-0.02$ \\
\hline$V_{p}, L$ & 516.912 & 522.69 & $429.16-619.93$ \\
\hline $\mathrm{IIV}_{\mathrm{V}_{\mathrm{p}}}(\mathrm{CV} \%)^{\mathrm{f}}$ & $0.001(6.07 \%)$ & $0.01(6.1 \%)$ & $0-0.07$ \\
\hline $\mathrm{Q}, \mathrm{L} / \mathrm{h}$ & $12.02 \mid$ & 17.37 & $7.85-40.65$ \\
\hline $\mathrm{V}_{\max }, \mathrm{mg} / \mathrm{h}$ & 376.164 & 480.68 & $44.91-1985.87$ \\
\hline $\mathrm{K}_{\mathrm{m}}, \mathrm{ng} / \mathrm{mL}$ & 107.083 & 4388.1 & $21.94-2183.12$ \\
\hline$I I V_{K m}(C V \%)^{£}$ & $0.348(7.22 \%)$ & $0.86(9.32 \%)$ & $0.07-4.01$ \\
\hline $\mathrm{CL}_{\mathrm{FO}}, \mathrm{L} / \mathrm{h}$ & 5.167 & 5.94 & $3.22-8.69$ \\
\hline$\epsilon, \mathrm{ng} / \mathrm{mL}$ & 0.296 & 0.29 & $0.21-0.35$ \\
\hline \multicolumn{4}{|c|}{$\begin{array}{l}\text { Abbreviations: } \mathrm{PK} \text {, pharmacokinetics; } \mathrm{Cl} \text {, confidence interval; Ka, absorption rate constant; IIV, inter-individual variation, } \mathrm{CV} \text {; coefficient of variation, } \mathrm{ALAGI} \text {, } \\
\text { absorption lag for depot compartment; } \mathrm{V}_{\mathrm{c}} \text {, central volume of distribution; } \mathrm{V}_{\mathrm{p}} \text {, peripheral volume of distribution; } \mathrm{Q} \text {, intercompartmental clearance; } \mathrm{V}_{\text {max, }} \text { maximum rate } \\
\mathrm{K}_{\mathrm{m}} \text {, Michaelis-Menten constant; } \mathrm{CL}_{\mathrm{FO}} \text {, apparent total clearance of the drug from plasma after oral administration; } \epsilon \text {, residual error. } \\
\dagger 95 \% \text { Confidence interval }(2.5 \%-97.5 \%) . \\
\AA:\left(\mathrm{CV}(\%)=\sqrt{\exp \left(\mathrm{omega}^{2}\right)-1} \times 100\right) .\end{array}$} \\
\hline \multicolumn{4}{|l|}{ (B) } \\
\hline Vc, L & 697.58 & 530.59 & |28.84-833.33 \\
\hline$I I V_{V_{c}}(C V \%)^{f}$ & $0.06(138.05 \%)$ & $0.87(9.37 \%)$ & $0.02-3.5$ \\
\hline$V_{p}, L$ & 351.78 & 876.22 & $184.33-2155.92$ \\
\hline$\| I V_{V_{p}}(C V \%)^{f}$ & $0.19(170.3 \%)$ & $0.16(6.57 \%)$ & $0.01-0.77$ \\
\hline $\mathrm{Q}, \mathrm{L} / \mathrm{h}$ & 1.17 & 0.94 & $0.23-1.84$ \\
\hline $\mathrm{Km}, \mathrm{ng} / \mathrm{mL}$ & 62.16 & 59.2 & $35.78-83.36$ \\
\hline $\mathrm{IIV}_{\mathrm{Km}}(\mathrm{CV} \%)^{£}$ & $0.82(585.57 \%)$ & 1.52 (I2.97\%) & $0.05-5.7 \mid$ \\
\hline $\mathrm{V}_{\max }, \mathrm{mg} / \mathrm{h}$ & 254.88 & 514.42 & $|40.6|-\mid 383.88$ \\
\hline $\mathrm{CL}_{\mathrm{FO}}, \mathrm{L} / \mathrm{h}$ & 3.39 & 2.38 & $0.62-4.6$ \\
\hline $\mathrm{D} 2, \mathrm{~h}$ & 97.44 & 89.61 & $50.21-111.21$ \\
\hline$\| \mathrm{IV}_{\mathrm{D} 2}(\mathrm{CV} \%)^{£}$ & 0.09 (144.4\%) & $0.13(6.47 \%)$ & $0-0.42$ \\
\hline ALAG2, h & 3.96 & 4.03 & $2.57-5.92$ \\
\hline $\mathrm{IIV}_{\text {ALAG2 }}(\mathrm{CV} \%)^{ \pm}$ & $0.13(154.1 \%)$ & $0.19(6.67 \%)$ & $0.01-0.53$ \\
\hline $\mathrm{F} 2_{\text {studyl }}$ & 0.13 & 0.17 & $0.08-0.31$ \\
\hline $\mathrm{F} 2_{\text {studyII }}$ & 0.18 & 0.17 & $0.1-0.2 I$ \\
\hline$\epsilon, \mathrm{ng} / \mathrm{mL}$ & 0.24 & 0.26 & $0.1-0.39$ \\
\hline
\end{tabular}

Notes: ${ }^{\dagger} 95 \%$ Confidence interval $\left.(2.5 \%-97.5 \%) . \stackrel{f}{ }{ }^{\mathrm{CV}}(\%)=\sqrt{\exp \left(\text { omega }^{2}\right)-1} \times 100\right)$.

Abbreviations: PK, pharmacokinetics; $\mathrm{Cl}$, confidence interval; $\mathrm{V}_{c}$, central volume of distribution; IIV, inter-individual variation, $\mathrm{CV}$; coefficient of variation, $\mathrm{V}_{\mathrm{p}}$, peripheral volume of distribution; $\mathrm{Q}$, intercompartmental clearance; $\mathrm{K}_{\mathrm{m}}$, Michaelis-Menten constant; $\mathrm{V}_{\text {max }}$ maximum rate; $\mathrm{CL}_{\mathrm{FO}}$, apparent total clearance of the drug from plasma after oral administration; D2, duration for central compartment; ALAG2, absorption lag for central compartment; F2, bioavailability for peripheral compartment; $\epsilon$, residual error. 
showed comparable PK profiles to those of the respective $5 \mathrm{mg}$ and $10 \mathrm{mg}$ oral regimens.

Simulation-predicted plasma concentrations were maintained without a significant decrease when the donepezil formulation was switched just after or $24 \mathrm{~h}$ after the last dose of multiple oral doses (Figure 3).

\section{Discussion}

PK simulation based on the chosen PK model predicted that a $175 \mathrm{mg}$ donepezil patch every 72 and $96 \mathrm{~h}$ would show a similar concentration profile to oral dosing with $10 \mathrm{mg}$ of donepezil every $24 \mathrm{~h}$, an $87.5 \mathrm{mg}$ patch every 72 and $96 \mathrm{~h}$ is similar to oral dosing with $5 \mathrm{mg}$ every $24 \mathrm{~h}$. Alternative 72 and $96 \mathrm{~h}$ patch regimens of with 87.5 and $175 \mathrm{mg}$ also showed similar PK profiles to with those with of $24 \mathrm{~h}$ PO oral regimens of $5 \mathrm{mg}$ and $10 \mathrm{mg}$, respectively.

The average concentration and $72 \mathrm{~h}$ interval AUC at steady state were slightly higher in the patch regimens than the corresponding oral dosing regimens, and the interindividual variability of the AUC and average

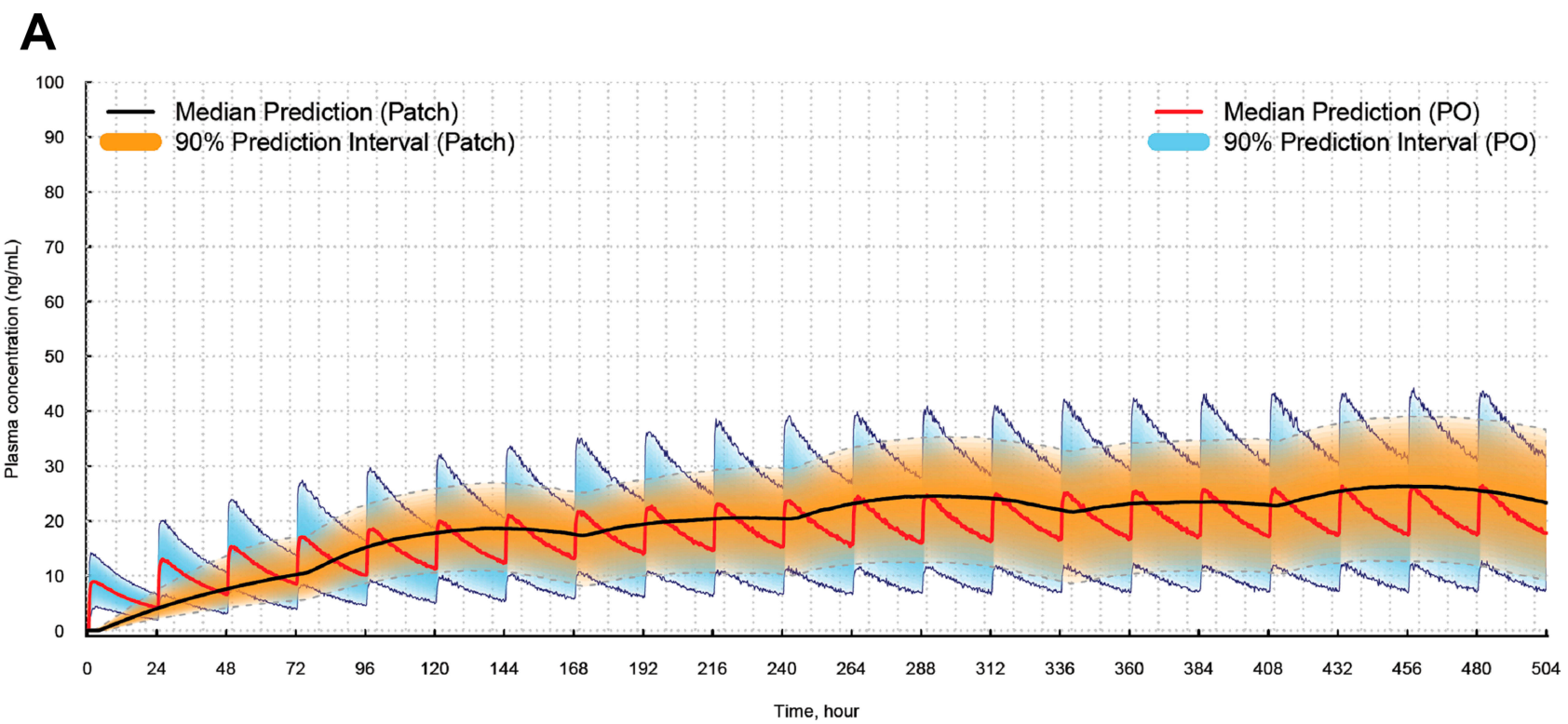

\section{B}

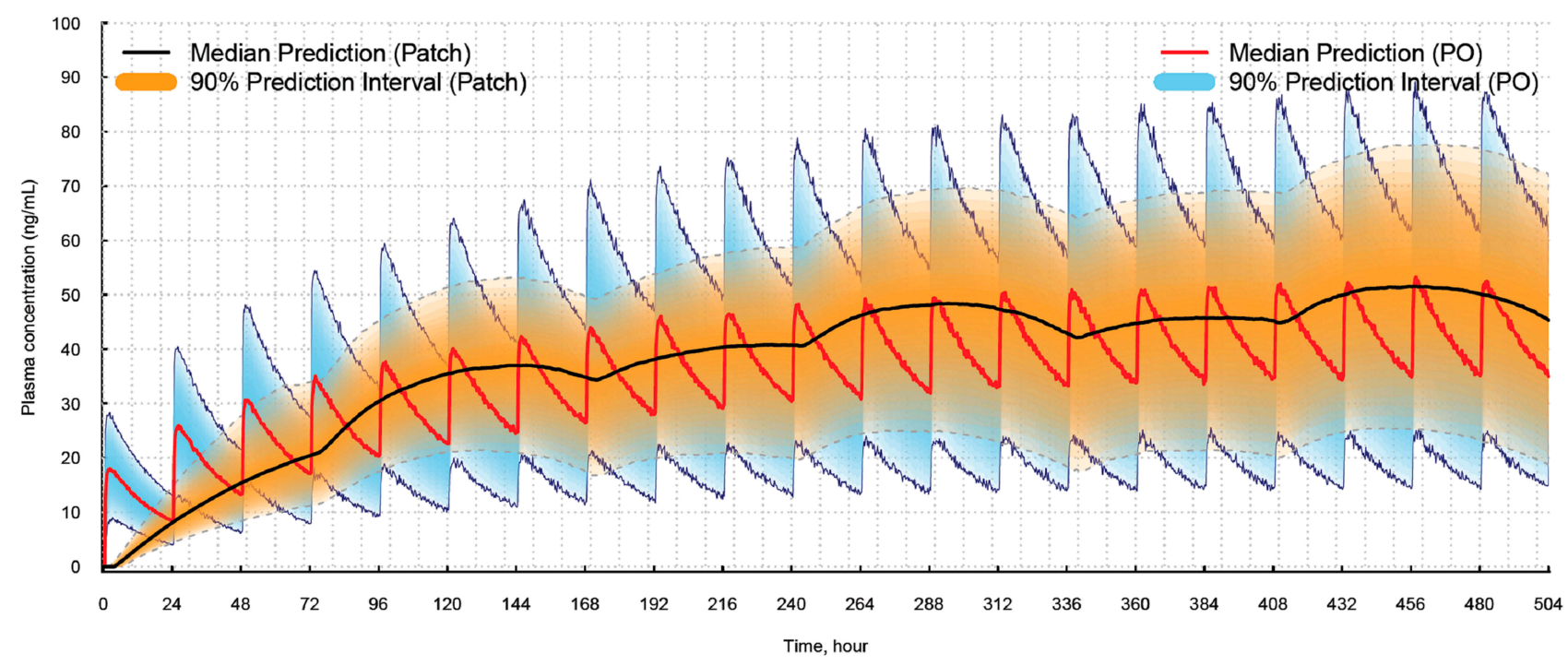

Figure 3 Model-predicted PK comparisons between oral formulation and patch. (A) donepezil $5 \mathrm{mg}$ oral formulations PO every $24 \mathrm{~h}$ or an $87.5 \mathrm{mg}$ donepezil patch every 72 and $96 \mathrm{~h}$ (dosing interval is alternatingly $72 \mathrm{~h}$ and $96 \mathrm{~h}$ ). (B) donepezil $10 \mathrm{mg} \mathrm{PO}$ every $24 \mathrm{~h}$ or a $175 \mathrm{mg}$ donepezil patch every $72 \mathrm{~h}$ and $96 \mathrm{~h}$ (dosing interval is alternatingly $72 \mathrm{~h}$ and $96 \mathrm{~h}$ ). Abbreviations: PK, pharmacokinetics; PO, per os. 
concentration was higher with the patch formulation than the oral, which possibly reflects higher inter-individual variability in BA when the patch is applied. However, the plasma concentration over time was much more stable in each individual after the patch application than after the oral formulation.

The absorption kinetics of oral donepezil is best described by a well-stirred model suggesting saturation kinetics during absorption phases with resultant higher concentrations than predicted by conventional firstorder absorption kinetics. Unlike the oral formulation, the transdermal absorption process after patch application was best described by a zero-order absorption model, and this reflects the physiologically different absorption process from the oral route showing the first-pass effect. Accordingly, the fluctuations in plasma concentrations were smaller with the patch formulation, and this PK characteristics of patch formulation potentially affect the toxicity and effectiveness profiles of donepezil.

The relative BA of the patch was estimated to be higher in study II than study I (F1 in NONMEM, 0.18 versus 0.13). In dose group 2 of study II, the donepezil patch was sealed with additional patches to keep the donepezil patch adhesive to skin, and this factor possibly increases the relative BA. However, the difference could also have originated from the difference in the accuracy of measurement of the drug concentration between the two studies.

\section{Conclusion}

In this study, we investigated the pharmacokinetic characteristics of oral dosing and patch form of donepezil. Standard goodness-of-fit plots, VPC, and bootstrap confirm that the model predicts the concentration well. Then, we performed the Monte-Carlo simulation. The results showed that $175 \mathrm{mg}$ of donepezil patch every 72 and $96 \mathrm{~h}$ would show a similar concentration profile to oral dosing with $10 \mathrm{mg}$ of donepezil every $24 \mathrm{~h}$, an $87.5 \mathrm{mg}$ patch every 72 and $96 \mathrm{~h}$ similar to oral dosing with $5 \mathrm{mg}$ every $24 \mathrm{~h}$. Also, we found that the PK regimens of $5 \mathrm{mg}$ and $10 \mathrm{mg}$, respectively, were similar to those of the PK regimens, respectively.

\section{Abbreviations}

ALAG, absorption delay; ALAG2, absorption lag for central compartment; ADUR, actual duration of patch application; BA, relative bioavailability; CI, confidence interval; CLFO, apparent total clearance of the drug from plasma after oral administration; $\mathrm{CV}$, coefficient of variation; DV, dependent variable; D2, duration of zero-order absorption; $\epsilon$, residual error; F2, bioavailability for peripheral compartment; FOCE, first-order conditional estimation method; IFF, baseline relative bioavailability; IIV, inter-individual variation; IPRED, individual predictions; $\mathrm{Ka}$, absorption rate constant; $\mathrm{Km}$, concentration at half maximum velocity; LC-MS/MS, liquid chromatographytandem mass spectrometry; PDUR, planned duration of patch application; PRED, population predictions; MM, michaelis-menten; PK, pharmacokinetic; Q, intercompartmental clearance; Vc, central volume of distribution; Vd, volume of distribution; Vmax, maximum velocity; Vp, peripheral volume of distribution.

\section{Data Sharing Statement}

We are sorry that we cannot share the data. The data are intellectual properties of the sponsor.

\section{Acknowledgments}

This work was supported by iCure Pharmaceutical Incorporated (Seoul, Republic of Korea), the manufacturer of the donepezil patch. The authors have had no financial relationships in the past 3 years with any organization that might have an interest in the submitted work, and there are no other relationships or activities that could have influenced the results and interpretation of the submitted work. The abstract of this paper was presented at the Alzheimer's Association International Conference as a poster presentation. The poster's abstract was published in "Poster Abstracts" in Alzheimer's \& Dementia. The URL is as follows:https://www.clinicaltherapeutics.com/article/ S0149-2918(17)30468-X/fulltext. This paper was checked and edited by Bioedit ${ }^{\circledR}$ LTD on the 15th December 2017.

\section{Funding}

This work was supported by the iCure Pharmaceutical Incorporated, Seoul, Republic of Korea.

\section{Disclosure}

HD, SK, YS, and YC were employees of iCure Pharmaceutical Incorporated at the time of the study. Ms Seok Kyu Yoon reports grants and non-financial support from iCure Pharmaceutical Incorporated, during the conduct of the study. Ms Dong Hyun Hong reports a patent 1017967710000 issued. Seong Su Kim reports a patent KR 


\section{0-1454362 issued. Dr Young Kweon Choi reports} a patent 1017967710000 issued. The authors report no other conflicts of interest in this study.

\section{References}

1. Small GW, Rabins PV, Barry PP, et al. Diagnosis and treatment of Alzheimer disease and related disorders. Consensus statement of the American Association for Geriatric Psychiatry, the Alzheimer's Association, and the American Geriatrics Society. JAMA. 1997;278 (16):1363-1371. doi:10.1001/jama.1997.03550160083043

2. Jingshu X, Stefano P, Nitin R, et al. Regional protein expression in human Alzheimer's brain correlates with disease severity. Commun Biol. 2019;2:34. doi:10.1038/s42003-018-0254-9

3. Seeley WW, Miller BL. Harrison's Principles of Internal Medicine. 2015.

4. Konstantina GY, Sokratis GP. Current and future treatments for Alzheimer's disease. Ther Adv Neurol Disord. 2013;6(1):19-33. doi:10.1177/1756285612461679

5. Brookmeyer R, Gray S, Kawas C. Projections of Alzheimer's disease in the United States and the public health impact of delaying disease onset. Am J Public Health. 1998;88(9):1337-1342. doi:10.2105/ajph. 88.9.1337

6. Francis PT, Palmer AM, Snape M, Wilcock GK. The cholinergic hypothesis of Alzheimer's disease: a review of progress. J Neurol Neurosurg Psychiatry. 1999;66(2):137-147. doi:10.1136/jnnp.66.2.137
7. Dooley M, Lamb HM. Donepezil: a review of its use in Alzheimer's disease. Drugs Aging. 2000;16(3):199-226. doi:10.2165/00002512200016030-00005

8. Stephen J, Richard JH, David W. The safety and tolerability of donepezil in patients with Alzheimer's disease. $\mathrm{Br} J$ Clin Pharmacol. 2004;58(s1):1-8. doi:10.1111/j.1365-2125.2004.01848.x

9. Burns A, Rossor M, Hecker J, et al. The effects of donepezil in Alzheimer's disease - results from a multinational trial. Dement Geriatr Cogn Disord. 1999;10(3):237-244. doi:10.1111/j.1365-2125. 2004.01848.x

10. Rogers SL, Farlow MR, Doody RS, Mohs R, Friedhoff LT. A 24week, double-blind, placebo-controlled trial of donepezil in patients with Alzheimer's disease. Donepezil Study Group. Neurology. 1998;50(1):136-145. doi:10.1212/wnl.50.1.136

11. Winblad B, Cummings J, Andreasen N, et al. A six-month doubleblind, randomized, placebo-controlled study of a transdermal patch in Alzheimer's disease - rivastigmine patch versus capsule. Int J Geriatr Psychiatry. 2007;22(5):456-467. doi:10.1002/gps.1788

12. Mercier F, Lefévre G, Huang HL, Schmidli H, Amzal B, AppelDingemanse S. Rivastigmine exposure provided by a transdermal patch versus capsules. Curr Med Res Opin. 2007;23(12):3199-3204. doi:10.1185/030079908X253438

13. Kim YH, Choi HY, Lim H-S, et al. Single dose pharmacokinetics of the novel transdermal donepezil patch in healthy volunteers. Drug Des Devel Ther. 2015;9:1419-1426. doi:10.2147/DDDT.S78555

14. Benet LZ, Zia-Amirhosseini P. Basic principles of pharmacokinetics. Toxicol Pathol. 1995;23(2):115-123. doi:10.1177/01926233950230 0203
Drug Design, Development and Therapy

\section{Publish your work in this journal}

Drug Design, Development and Therapy is an international, peerreviewed open-access journal that spans the spectrum of drug design and development through to clinical applications. Clinical outcomes, patient safety, and programs for the development and effective, safe, and sustained use of medicines are a feature of the journal, which has also

\section{Dovepress}

been accepted for indexing on PubMed Central. The manuscript management system is completely online and includes a very quick and fair peer-review system, which is all easy to use. Visit http://www. dovepress.com/testimonials.php to read real quotes from published authors. 